\title{
Green Information and Communication Technology Standards Development: An India Perspective
}

\author{
Ritesh Kumar Kalle ${ }^{1}$ and Arvind Mathur ${ }^{2}$ \\ ${ }^{1}$ NEC India Pvt. Ltd., India; email: ritesh.kumar@necindia.in \\ ${ }^{2}$ Cisco Systems, India; email: arvmathu@cisco.com
}

Received July 2013; Accepted August 2013

\begin{abstract}
Green Information and Communication Technologies (GICT) refers to the wide-ranging spectrum of environmentally friendly technologies that power the connected information infrastructure globally. The GICT Working Group (WG) within GISFI brings the stakeholder's standpoints to the standardization forum and seeks to evolve the most suitable approach for adoption in the Indian context. The WG also aims to develop specifications in specific areas where existing global standards do not meet Indian requirements. In this paper, an overview of GICT WG activities is provided along with the current progress of important work items from an Indian standards development perspective. The paper also outlines the collaboration of the GICT WG with external organizations and presents a structured roadmap of technical specifications development.
\end{abstract}

Keywords: GICT, Energy Efficiency Metrics, Telecommunications.

\section{Introduction}

Green Information and Communication Technology (GICT) is a Working Group (WG) of Global ICT Standardisation Forum for India (GISFI) since

Journal of ICT Standardization, Vol. 1, 205-220.

doi:10.13052/jicts2245-800X.12a6

(C) 2013 River Publishers. All rights reserved. 
its inception in 2009. This WG has developed three Technical Reports (TRs) [1], [2] and [3] and twoTechnical Specifications (TSs) [4] and [5]. GICT WG of GISFI has liaised with global Standards Developing Organizations (SDOs) and is working closely with organizations such as the Telecommunication Engineering Centre (TEC) under the Department of Telecommunications, Government of India.

Activities of the GICT WG of GISFI are of the utmost importance for India because ICT is one of the fastest growing sectors in the Indian economy (it contributed approximately seven percent of the Indian GDP in 2012 [8]), as well as in the world. However, the growth of ICT is a double edged sword for India: while it brings economic growth and solutions that curb the growth of Green House Gases (GHG) in other industry sectors, in itself it also contributes to pollution and impacts the environment and economy in various ways. In India, around 4\% of the GHG emission is from the ICT sector which is around 80 million tonnes of $\mathrm{CO}_{2}$ emission every year. Around $25 \%$ of this emission, i.e., $1 \%$ of the GHG emission is from the telecom sector which is around 20 million tonnes of $\mathrm{CO}_{2}$ [9].Thus there are two important aspects regarding Green ICT in India: (1). Making ICT green, and (2). Using ICT technology towards making other industry sectors green.

This paper begins with a section on the scope and objectives of the GICT WG. Thereafter, in the third section a brief outline of the achievements of GICT WG is provided. Next, in the fourth section, ongoing collaborative activities with the Government of India and Global SDOs are described. In the fifth section, the planned activities of the GICT WG in the near future are outlined. The sixth and final section concludes this paper.

\section{Scope and Objectives}

Green ICT applies tothe entire lifecycle of products starting from the design, to production (material and method of production), operations and goes on further to the product end of life or recycling phase. Since this spectrum was far too wide for the Green ICT WG to address effectively in the initial phase of its activity, it was decided by the WG to retain focuson (a). Greening the ICT infrastructure during its usage and (b). Identifying means to use ICT to make other industry sectors green. Thus technical and standards considerations related to the complete lifecycle of product; materials and substances used for product development and recycling were designated 'out of scope' for the GICT WG in its initial set of work items.Further, the activities of the GICT WG were guided by the technical expertise; understanding of global 
business implications for India; and the interpretation of unique requirements for Green ICT in India by its members, driven by a mechanism based on GISFI member consensus that represented corporates, individual contributors and academia. Significant technical contributions to the WG were received from corporate members NEC, Ericsson, Cisco, VNL, I2TB-SPPL and Graceful Growth Consulting Services; individual contributors and academic institutions like IIIT-Allahabad.

The following are the stated objectives of the GICT WG:

i. Define metrics and methods of measurement for energy efficiency of telecommunications equipment;

ii. Study potential enhancements of ICT for making it green; and

iii. Study potential use of ICT to make other sectors green (ex: Agriculture, Transport).

\section{GICT WG Contributions}

Over the last three years, the GICT WG along with stakeholders has put forth significant efforts to carry out detailed study of the standards landscape, regulations and India-specific requirements of energy efficient ICT. Figure 1 illustrates a map of significant contributions in terms of technical reports and specifications proposed by the GICT WG. In this section, an overview of activities of the WG in the following three major areas of focus has been provided:

Subsection 3.1: Metrics and methods of measurement for energy efficiency of telecommunication equipments

Subsection 3.2: Study on potential enhancements of ICT

Subsection 3.3: ICT to make other sectors green

Complete descriptions of the contributions listed in Figure 1 are available in the documents listed in the References.

\subsection{Metrics and Methods of Measurement for Energy Efficiency of Telecommunication Equipments}

The WG has produced one approved technical report and two technical specifications in this area which have effectively formed the baseline for the national green telecom implementation plan of the TEC in India. The technical report [3] surveys the existing work at various international standard development organizations such as the International Telecommunication Union (ITU), 

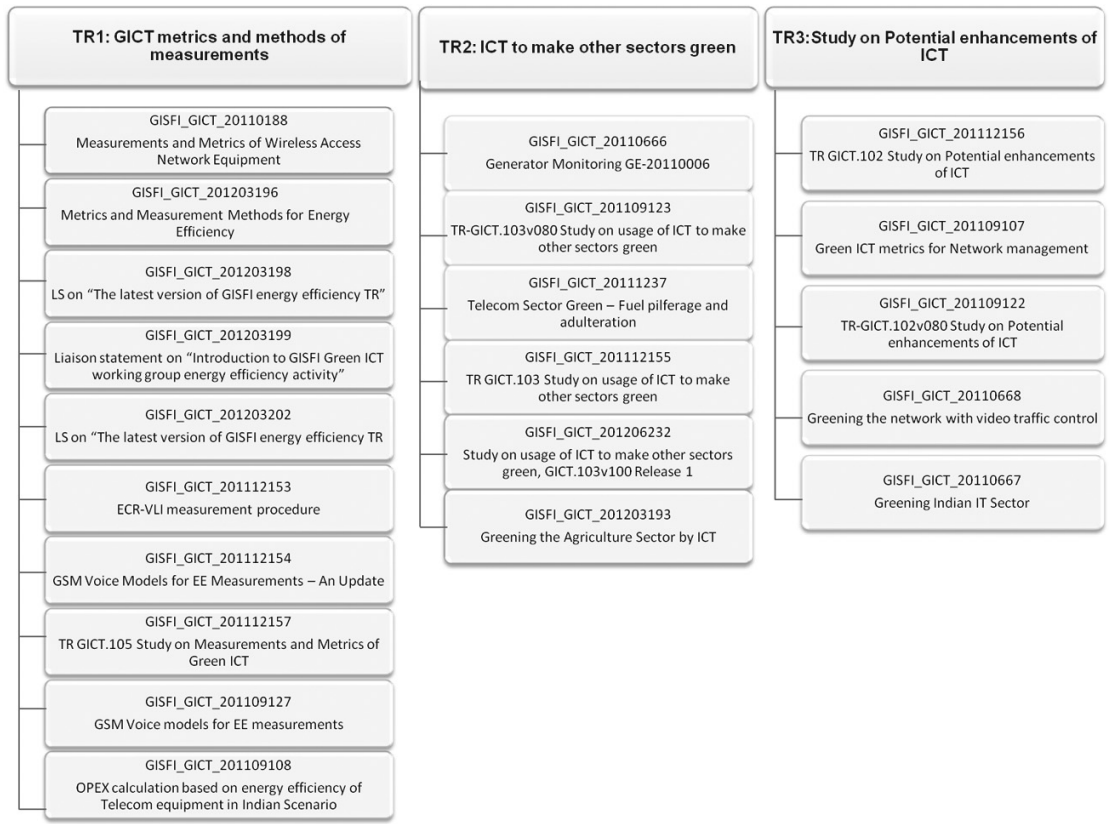

Figure 1 Standards development - GICT WG contributions map [7].

Alliance for Telecommunications Industry Solutions (ATIS) and European Telecommunications Standards Institute (ETSI). It also surveys the Telecom Regulatory Authority of India (TRAI) recommendations towards implementation of green telecommunication in India. More specifically, it describes the metrics and method of measurement for circuit switched broadband equipment (DSLAM) and GSM radio base station. The gaps in the current standards as well as TRAI recommendations are outlined towards the end of this technical report.

\subsubsection{End-to-End Landscape of Global GICT Standards}

Figure 2 illustrates the span of global standards from ETSI/ITU/ATIS across access network, core network and the data centres that form the complete end to end network topology of any telecom service provider.

As can be inferred from Figure 2, it is apparent that no single standard covers the entire span of the telecom network and therefore efforts such as those done by the GICT WG are needed to stitch together the range of ICT standards applicable to India. While leveraging the existing global standards, 


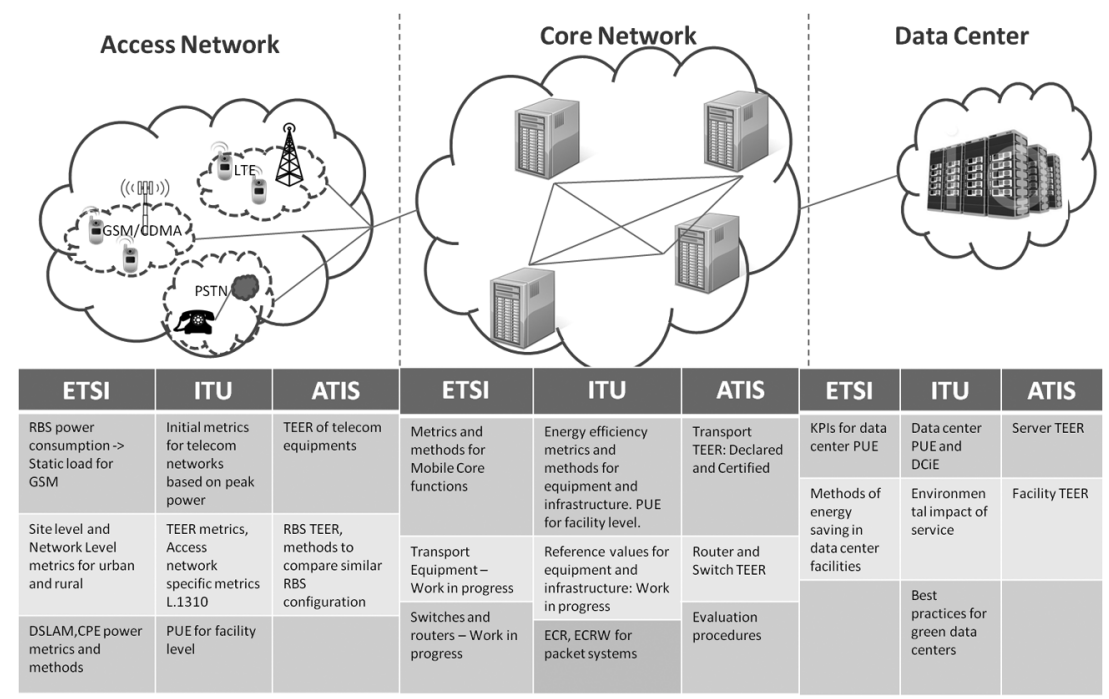

Figure 2 Survey of existing global standards and their applicability to telecommunication equipments [7].

it is also very important to fill the gaps with new or modified standards relevant for Indian telecom networks.

\subsubsection{Classification of Telecommunication Equipments}

While considering the standards applicable to the end-to-end telecom infrastructure, it is also important to classify and prioritize telecommunication equipments in order to recommend or generate appropriate technical standards. In this context, the GICT WG has delivered Technical Specification (TS) [5] that detail the classification of telecommunication equipments for the purpose of energy efficiency measurement. Table 1 shows the classification model for telecommunications equipment developed by the WG under the TS.

\subsubsection{Radio Base Station Energy Efficiency Metrics}

If we focus on the access network side of the telecom service provider infrastructure, the Radio Base Stations (RBS) stands out as one of the most energy consuming class of telecom equipment. This is especially significant from the Indian context because of the very large installed base of RBSs (more than 400,000 sites [14]) and coupled with the acute shortage of grid power, this class of telecom equipment is considered to be of the highest priority for the energy efficiency standards activity. However,if the energy efficiency 

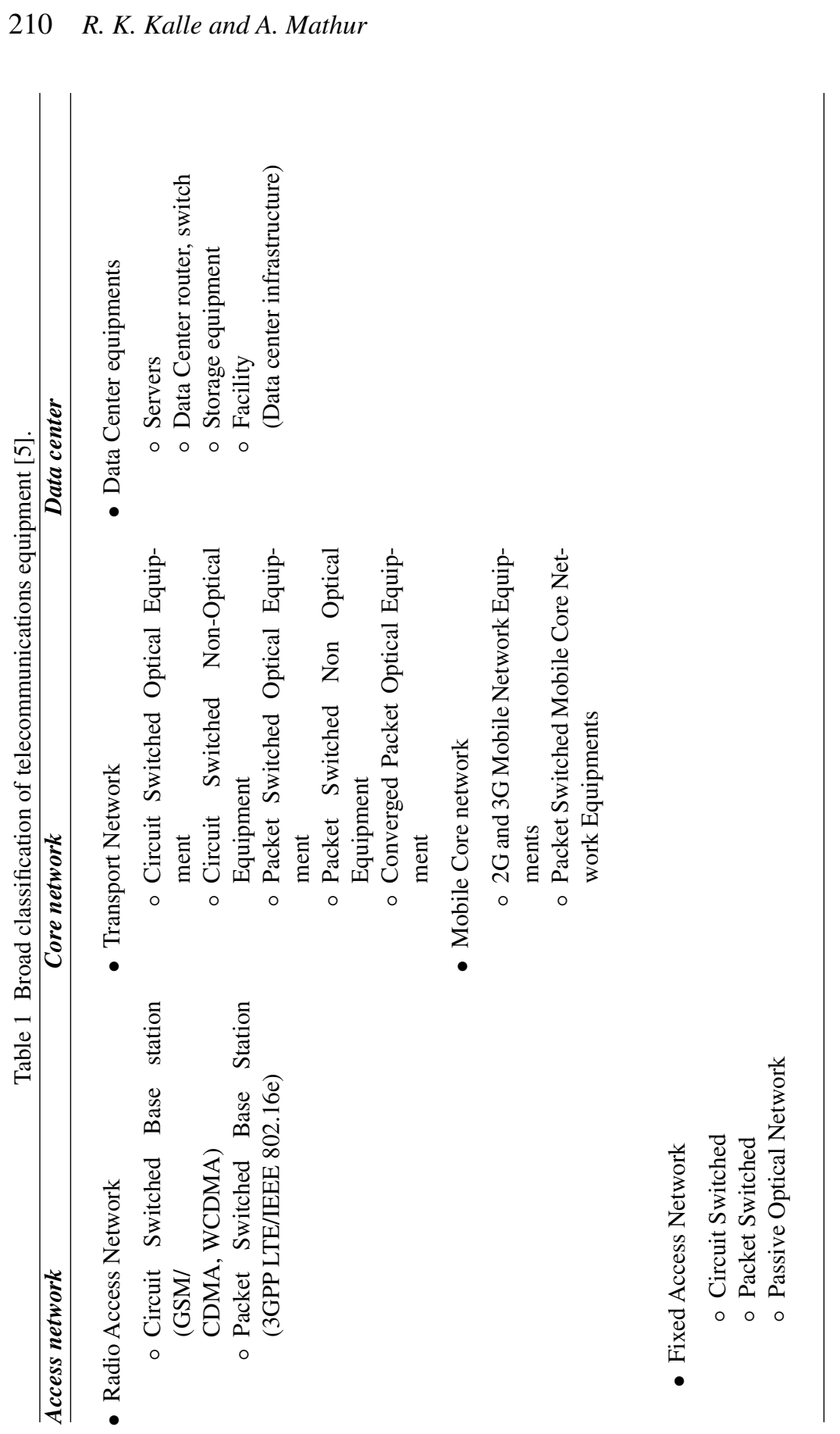
standards from ETSI/ATIS/ITU on RBS equipments are studied in detail, it is revealed that no single global standard can effectively address all Indian requirements. An overview of the comparative analysis of specifications on RBS energy efficiency metrics from various global SDOs is shown in Table 2. GISFI GICT WG is actively progressing towards framing of specifications that address all the Indian requirements related to the RBS energy efficiency metrics and methods of measurements.

The GISFI GICT Technical Specification [4] is an umbrella document that spells out the general requirements for measurement setup, procedures, reporting format and assessment scales.The GICT WG follows the ITU's general definition of energy efficiency metric for telecom equipments [11]. Further, the document also provides the generalized definition of Energy Efficiencybased on which subsequent specifications would address the requirements of each class of equipments.

The general definition for metric by ITU is: "Energy efficiency will be defined as the relationship between the specific functional unit for a piece of equipment (i.e., the useful work of telecommunications) and the energy consumption of that equipment." [11]

General Definition of Energy Efficiency $=\frac{\text { Useful Work Done }}{\text { Power Consumed by Equipment }}$

\subsection{Study on Potential Enhancements of ICT}

The GICT WG has produced one TR[1] on the study on potential enhancements of ICT sector to make it more environmentally friendly. It surveys the related topics of Green Energy and GHG Emission. Further, the TR describes the ongoing activities in ICT standardization and potential areas of improvements. Both the telecom sector as well as the broader ICT sector has been addressed in this report, and potential gaps in the current standards and scope for enhancement within the purview of GICT WG activities are addressed.The various components of ICT and their $\mathrm{CO}_{2}$ emissions in the ICT sector and their footprints are shown in Figure 3.

GICT is the study and practice of designing, manufacturing, using and disposing of computers, servers, and associated subsystems-such as monitors, printers, storage devices, and networking and communications systemsefficiently and effectively with minimal or no impact on the environment. Thus, Green IT includes the dimensions of environmental sustainability, the economics of energy efficiency, and the total cost of ownership, which includes the cost of disposal and recycling. Figure 4 shows the percentage of benefit by practicing green IT. 


\section{R. K. Kalle and A. Mathur}

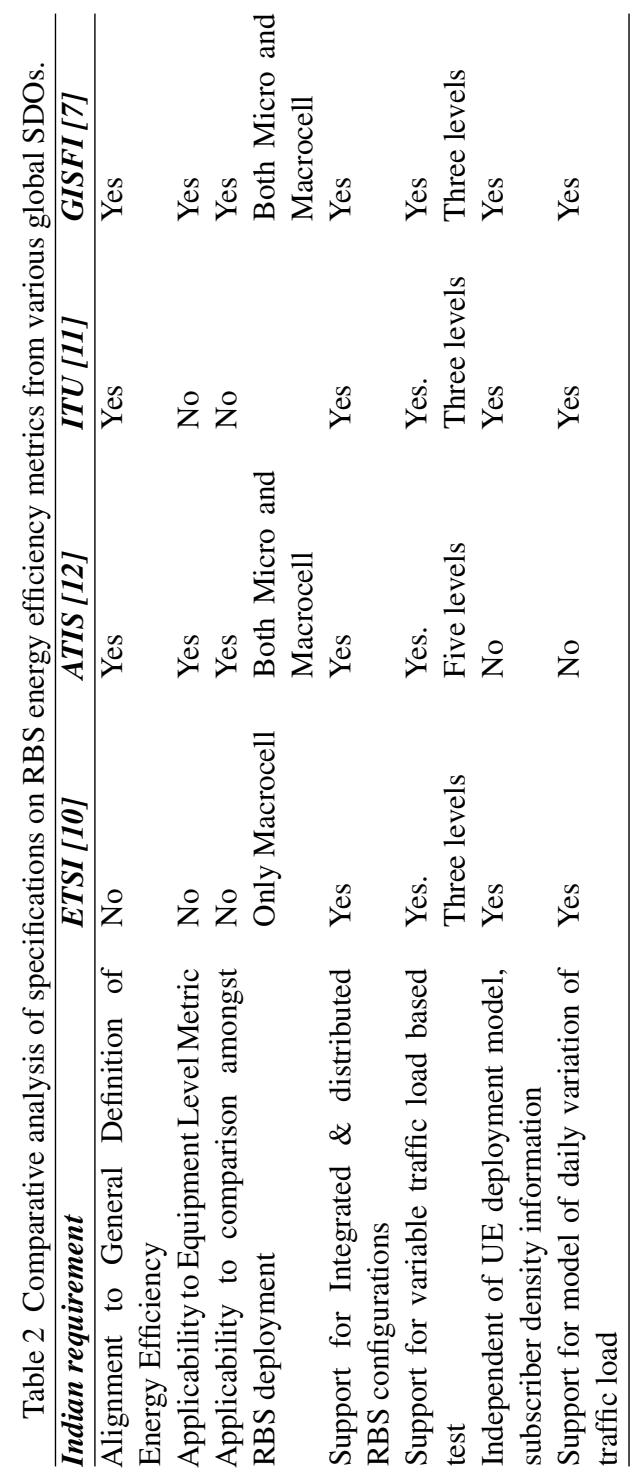




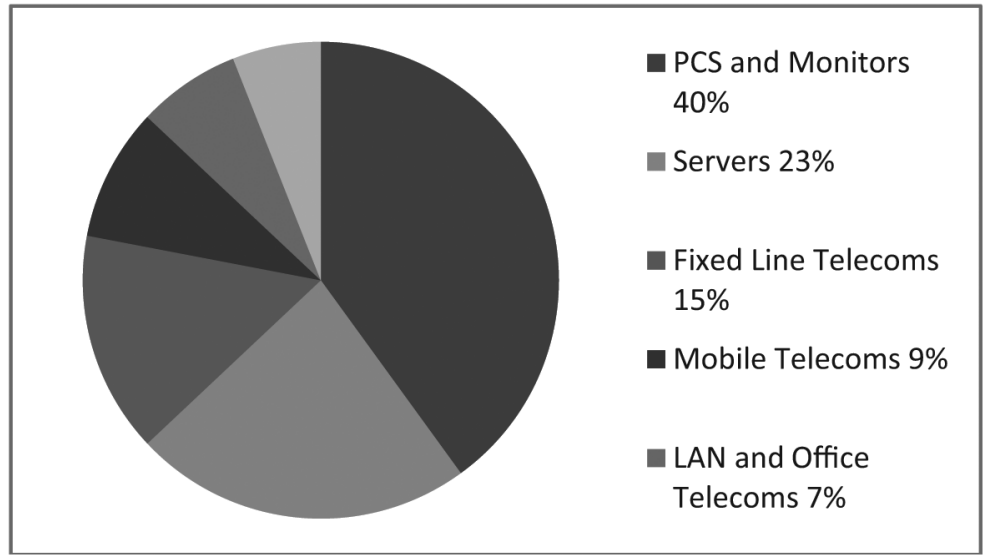

Figure 3 Distribution of $\mathrm{CO}_{2}$ emissions in IT sector [9].

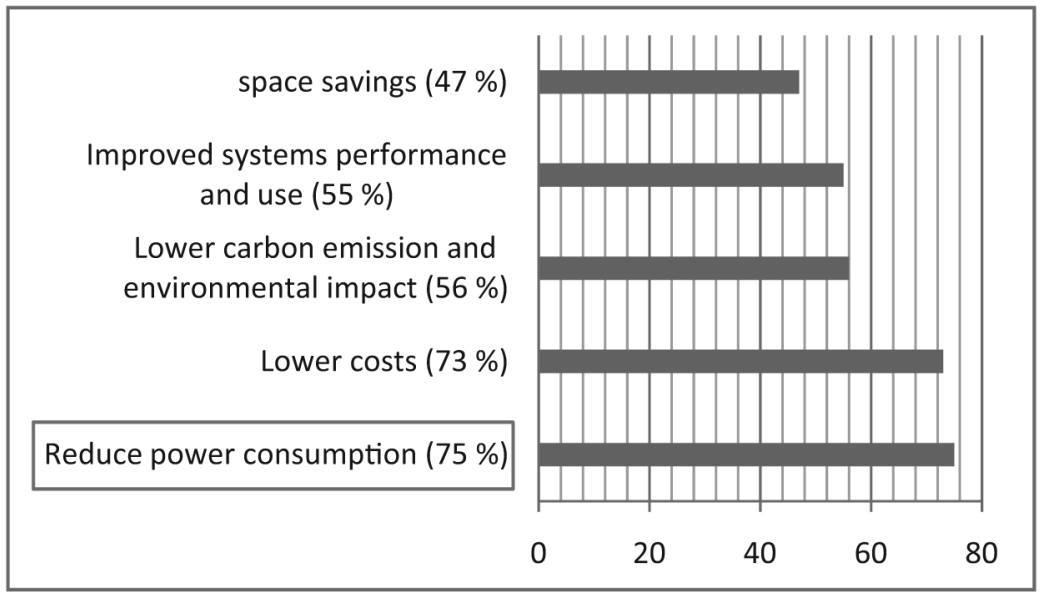

Figure 4 Green ICT adoption benefits [7].

Energy efficiency initiatives in ICT have mostly focused on consumption while in use. However, a large part of the environmental impact of a device comes during its manufacturing and disposal. The whole life impact of equipment is much more difficult to measure than the in use energy consumption, because it is spread through a long supply chain. Figure 4 depicts the benefits of adopting Green ICT technologies. It is clear that reducing power consumption of equipments is the biggest contributor to the benefits possible from Green ICT adoption hence it is the single most important factor to consider while 


\section{R. K. Kalle and A. Mathur}

looking to enhance the energy efficiency of telecommunications equipment. By conserving energy, GHG emissions can also be reduced significantly and also potentially reduces cost of operation for different ICT products and solutions. Understanding current ICT scenario in India enables to set the goals for reduction in carbon emissions and providing solutions that require minimum power for satisfying the user requirements.

\subsection{ICT to Make Other Sectors Green}

The scope of the GISFI Technical Report [2] produced on this topic is a study on the means to use ICT to make other sectors green. The TR identifies ongoing standardization activities worldwide on the topic of using ICT to make other sectors green. Further Indian scenarios are studied and requirements on using ICT to make other sectors green are identified. Sectors within the scope of the technical report are: Power sector, Transportation, Manufacturing, Agriculture, E- Education, Data-centres.

India was ranked fifth globally in total GHG emissions, behind the United States, China, the European Union and Russia in 2007. The emissions of the United States and China were four times that of India. The largest portion of India's GHG emissions comes from the energy sector. In 2007, energy accounted for about $57.8 \%$ of total $\mathrm{CO}_{2} \mathrm{e}$ emissions - of which almost $65 \%$ from electricity supply (includes power for various industries through captive generation including telecom sector), $12.6 \%$ from residential and industrial fuel combustion and around $12.9 \%$ from transport. Road transport accounted for nearly $87 \%$ of transport emissions (the remaining $13 \%$ coming from rail, aviation and shipping). Of the other sectors, agriculture accounted for $17.6 \%$ of total emissions in 2007 (around 22\% in 2005), industrial process emissions contributed around $21.7 \%$, waste disposal accounted for $3 \%$ (falling from nearly $7 \%$ in 2005), and land use and land use change (LULUCF) accounted for $9 \%$ (net carbon storage in 2007). Figure 5 shows a sector-wise breakdown of emissions for 2007 [13].

There are opportunities for reducing emissions through intensive use of ICT across many sectors like energy creation and distribution, buildings, transport and industry. Preparing core ICT infrastructure for these technologies is critical. ICT can be used for disaster relief/early warning and for emergency services, which are particularly important in mitigating the effects of climate change, for instance from flooding or increased incidence of violent storms and hurricanes.In the initial phase, GISFI GICT WG has been working in the following sectors to reduce GHG emissions: 


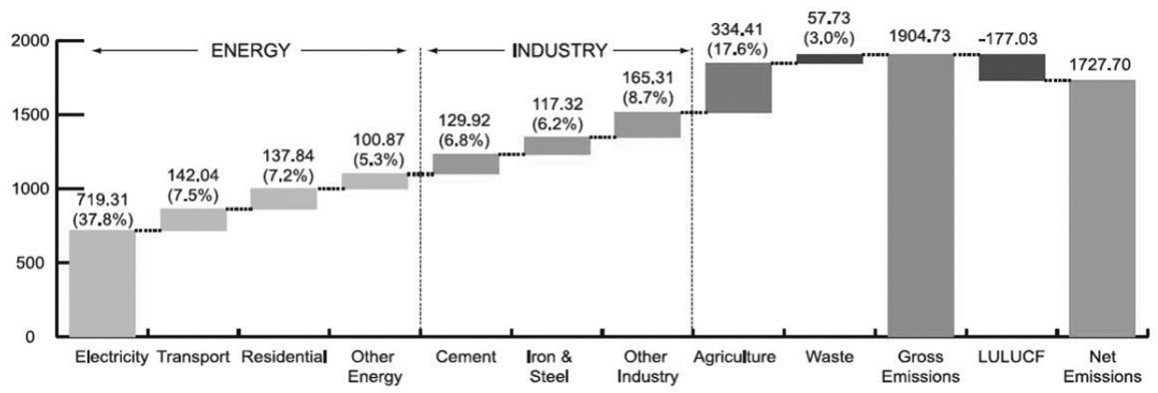

Figure 5 Sector wise GHG emissions in 2007 (million tons of $\mathrm{CO}_{2}$ eq) [13].

- Telecom Sector

- Energy Sector

- Transport Sector

- Agriculture Sector

- e-Education Sector

\section{Collaboration with Government and Other SDO's}

The GICT WG has forged strong working relationship with Government of India organizations like the TEC, Department of Telecommunications. GISFI members actively participate in the core committee setup by the TEC towards formulating the guidelines for the implementation of Green Passport certification for telecommunication equipments in India. The Figure 6 shows the most important outputs from the GICT WG. In the period from 2011 to 2013, the WG has released three TRs and two TSs on topics described in the Section 3. It may be noted that the GICT standardization is an ongoing process in which stakeholders comprising industry, government and academia are closely working with each other to develop specifications and standards.

The GICT WG has also sent liaison statements to the ITU-T Study Group 5 as well as other SDOs such as ATIS to collaborate closely on measurement metrics and methods of energy efficiency for telecom equipments. Global SDO representatives like the ITU-T SG5 have participated in the GISFI Standardisation Series Meetings in the past and have committed their support for GISFI activities. 


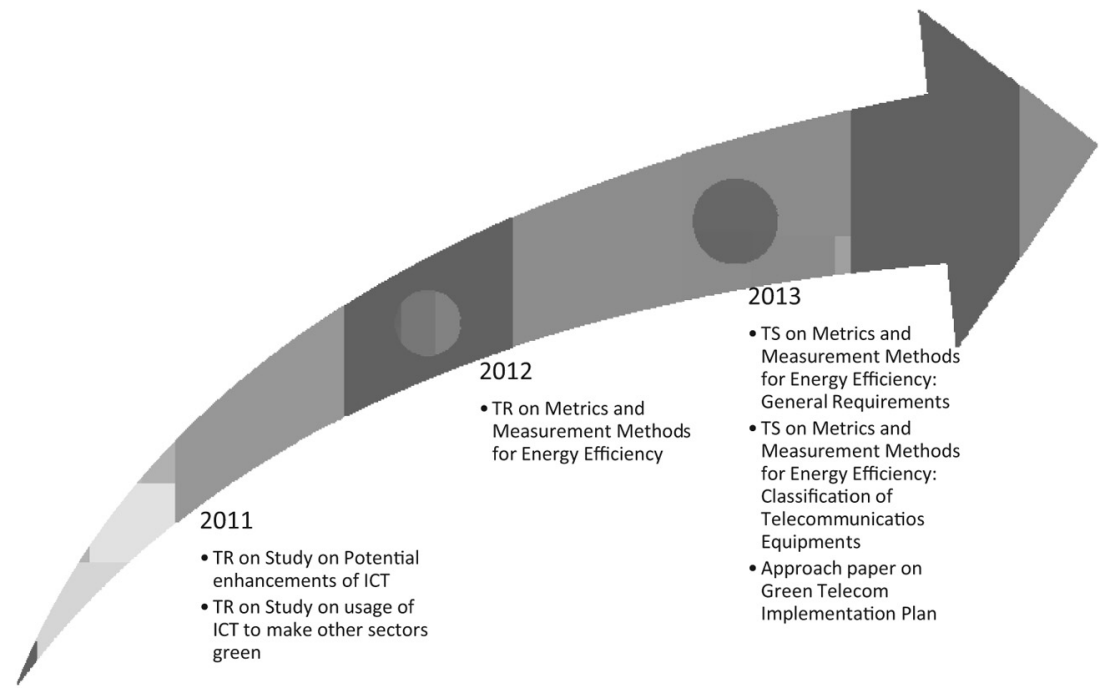

Figure 6 Key contributions from the GICT WG [7].

\section{Future Plans}

The GICT WG has a well-defined roadmap for specifications and standards development. Figure 7 shows the GISFI GICT WG Standards Roadmap for the creation of technical specifications in the focus area of telecom equipment energy efficiency. In addition, the GICT WG in partnership with government organizations such as the TEC, would help spearhead the green telecom standardisation and certification efforts in India.

Development of the following GISFI Technical Specifications (Table 3 and Table 4) are forthcoming in the near term based on the urgency and prioritization of efforts determined by stakeholders across the Government of India, Industry and Academia:

\section{Conclusions}

This paper reviewed the importance of developing Green ICT Standards for India, and provided an overview of efforts of GISFI by citing Technical Specifications and Technical Reports developed by the Green ICT Working Group. The longer-term work plan of the GICT WG was elucidated via a Standards Development Roadmap that was constructed in consultation with its stakeholders. GISFI GICT Working Group continues to work intensively 


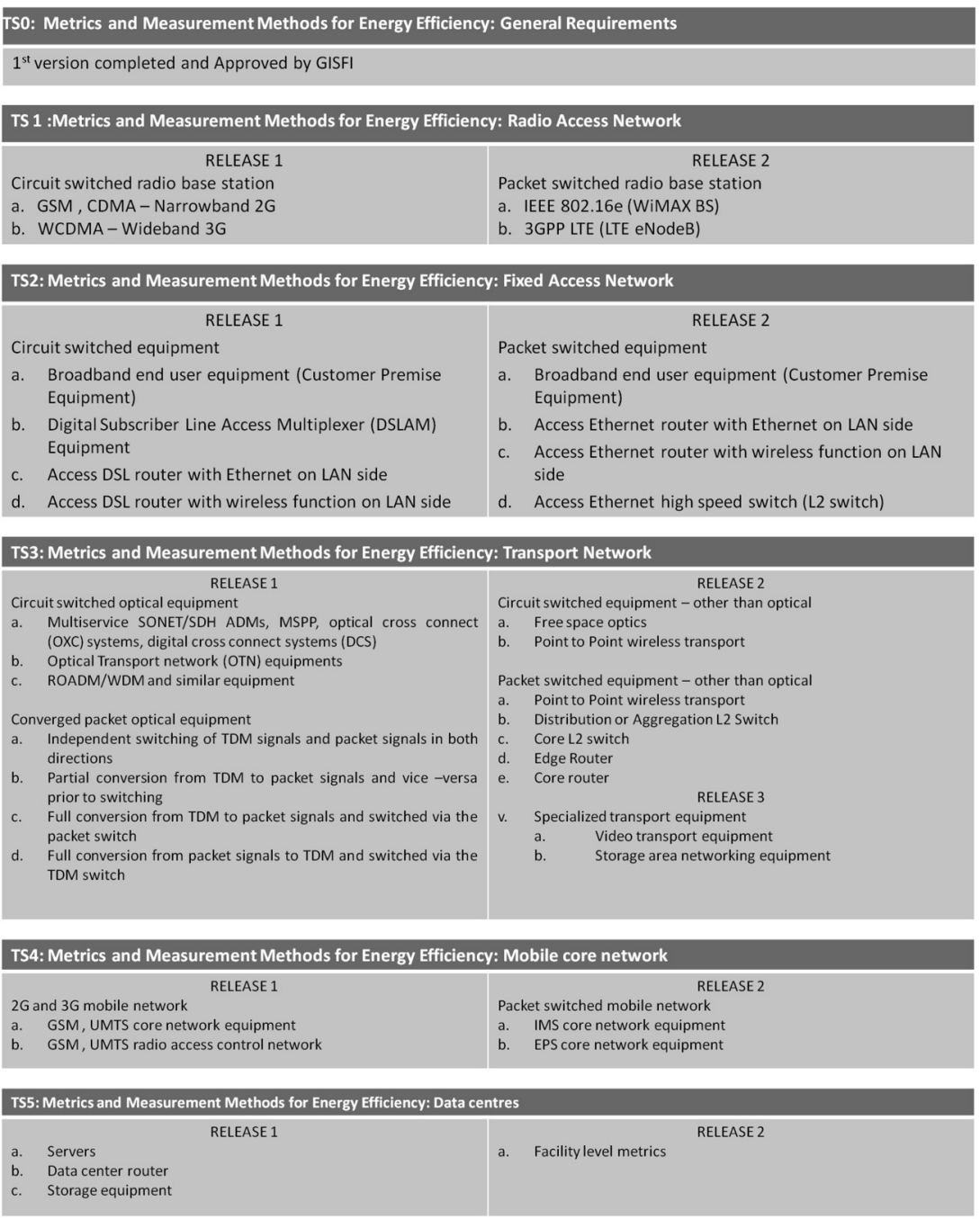

Figure 7 GICT WG standards roadmap [7].

Table 3 TS on metrics and measurement methods for energy efficiency: radio access network.

Release 1

Circuit switched network radio base station

a. GSM, CDMA - Narrowband $2 \mathrm{G}$

b. WCDMA - Wideband $3 \mathrm{G}$
Release 2

Packet switched network radio base station

a. IEEE 802.16e (WiMAX BS)

b. 3GPP LTE (LTE eNodeB) 
Table 4 TS on metrics and measurement methods for energy efficiency: ip router and switch.

\begin{tabular}{ll}
\hline Release 1 & Release 2 \\
\hline a. Access and Edge Router & a. Core router \\
b. Access and Distribution Switch & b. Core and data center switch \\
\hline
\end{tabular}

with stakeholders to achieve the goals illustrated in the roadmap. Green ICT is an area of great importance and focus for the Nation of India, the Industry, Research Fraternity, Policy Makers and Academia alike. The efforts of GISFI and those of the GICT WG are aligned to the overarching goal of creating a green and sustainable planet and delivering the promise of ICT technologies through standards development that will drive global adoption.

\section{References}

[1] GISFI TR GICT.102 V1.0.0, Study on Potential enhancements of ICT; Release 1, December 2011.

[2] GISFI TR GICT.103. V1.0.0, Study on usage of ICT to make other sectors green; Release 1, September 2011.

[3] GISFI TR GICT.105 V1.1.0, Metrics and Measurement Methods for Energy Efficiency; Release 1, December 2012.

[4] GISFI TS GICT.100 V1.0.0, Metrics and Measurement Methods for Energy Efficiency: General Requirements; Release 1, January 2013

[5] GISFI TS GICT.101 V1.0.0, Metrics and Measurement Methods forEnergy Efficiency: Classification of Telecommunication Equipments; Release 1, February 2013

[6] Approach towards Implementation of Green Telecom in India, GISFI GICT WG, January 2013.

[7] GISFI Meeting Documents: Green ICT URL: http://gisfi.org/workinggroups.php?wg= GICT [Last accessed: $13^{\text {th }}$ July, 2013]

[8] Indian IT-BPO Industry, NASSCOM URL: http://www.nasscom.in/indian-itbpo-industry [Last accessed: $13^{\text {th }}$ July, 2013]

[9] Recommendations on Approach towards Green Telecommunications, TRAI URL: http://trai.gov.in/Content/RecommendationDescription.aspx?RECOMEND_ID=232\& qid $=0$ [Last accessed: $13^{\text {th }}$ July, 2013]

[10] ETSI TS 102706 V1.2.1; (10/2011); Environmental Engineering (EE); Measurement Method for Energy Efficiency of Wireless Access Network Equipment.

[11] ITU recommendation: L.1310; (11/2012); Energy efficiency metrics and measurement for telecommunication equipment.

[12] ATIS-0600015.06.2011; (11/2011): Energy efficiency for telecommunication equipment: Methodology for measurement and reporting of radio base station metrics.

[13] Ministry of Environment and Forests, Government of India, India: Greenhouse Gas Emissions 2007 URL: http://moef.nic.in/downloads/public-information/Report_INCCA.pdf [Last accessed: $13^{\text {th }}$ July, 2013]

[14] Powering Cellular Base Stations: A Quantitative Analysis of Energy Options- Prof. Ashok Jhunjhunwala, RITCOE- IIT Madras Solar PV, Diesel Generators, Batteries and 
Electrical Grid URL: http://www.tcoe.in/download/1/Download-Section_190/1/1.html [Last accessed: $13^{\text {th }}$ July, 2013]

\section{Biographies}

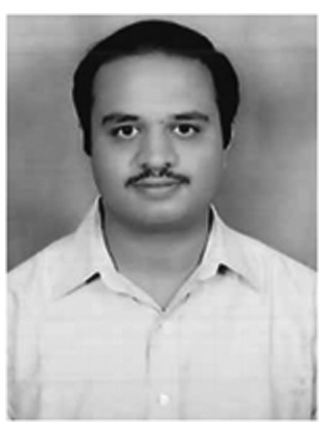

Ritesh Kumar Kalle is Research Engineer at NEC Mobile network Excellence Center (NMEC), Chennai, India. Prior to this, he was the Senior Scientific Officer and a full time PhD scholar in Wireless Networks Lab at IIIT-Bangalore. He primarily works in related areas of modelling and performance analysis of Mobility, Power Saving and Quality of Service in Wireless networks, particularly LTE, WiMAX and Wi-Fi. His research was supported by Microsoft Corporation under the Microsoft Research India PhD Fellowship Award and the Departmentof Information Technology, Govt. of India. Ritesh has a graduate degree in Information Technology from IIIT-Bangalore. He has applied several patents and has published extensively in peer reviewed International Journals and Conferences.

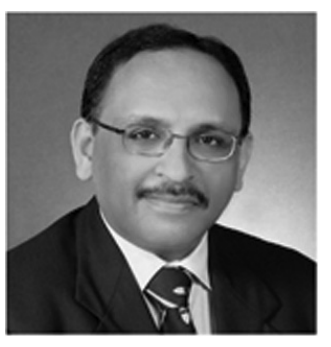

Mr. Arvind Mathur is Strategic Technology Officer, India \& South Asia with Cisco's Corporate Research \& Advanced Development Group and is based in Bangalore, India. Arvind's professional career spans over 23 years in the telecom \& ICT industry and he brings extensive service provider executive leadership experience from India as well as internationally. Prior to joining Cisco in 2010, Arvind was CTO and President, Global Services at

Sify Technologies; CTO at Bharti Airtel for Enterprise Services; and Vice President \& Global Head of Product Management for Enterprise Network Services at Tata Communications, formerly Tata-VSNL.

Arvind has spent several years in Japan, USA and Canada working in different roles and capacities with the Research Institute of Electrical Communications, Teleglobe International, and JDS Uniphase. At Cisco, he is working on several initiatives for Service Providers, Public Sector and Government Affairs, contributing to thought leadership in technology, service architectures, 
solutions, standards and policy. Arvind is a familiar industry speaker on next generation converged ICT networks, Internet of Everything/Internet of Things, cloud computing, data centers, managed services and innovation strategies. Arvind is an alumnus of the Indian Institute of Science, Bangalore and the Indian Institute of Technology, Delhi. 